\title{
Treatment of hepatic encephalopathy
}

\author{
P. J. TOGHILL \\ M.D., M.R.C.P.
}

The treatment of acute hepatic coma by exchange transfusion

The mortality of coma complicating acute hepatic necrosis remains high at about $80 \%$ and recently exchange transfusion has shown some promising results. This line of treatment is based on the assumption that improvement depends on the removal of non-dialysable toxic substances from the circulation although some authors have suggested that the benefit might be due to the addition of deficient factors such as antibody (Morris, Gocke \& Sardi, 1967).

In fact the first successful treatment of hepatic coma by exchange transfusion was more than 10 years ago (Lee \& Tink, 1958) but there has been a resurgence in interest in this therapy following the complete recovery of six patients out of eleven treated by Trey, Burns \& Saunders (1966). Other workers have failed to achieve such good results (Jones et al., 1967) but the relative simplicity of the method and the high mortality of coma in acute necrosis would seem to indicate its use in patients not responding to conventional measures of protein restriction and gut sterilization.

The majority of reports indicate that exchange of at least one blood-volume must be carried out for appreciable clinical improvement to occur and this must be repeated on subsequent days. Whenever possible fresh citrated blood should be used but exchange transfusion may be complicated by coagulation defects due to both the hepatitis and the actual blood exchange itself (Samson et al., 1967). The same authors have discussed the importance of hypoglycaemia which may also extend the hazards of exchange transfusion in hepatic necrosis.
We have had the opportunity of treating five patients with exchange transfusion (Table 1). Three of these patients had coma complicating acute hepatic necrosis and two had very severe portosystemic encephalopathy complicating cirrhosis. In retrospect the volumes of blood exchanged may have been too small and the procedure performed too late.

The technical difficulties of obtaining fresh matched blood may be avoided by plasma-exchange which has been exploited by Sabin \& Merritt (1968). They removed the patient's plasma and returned the patient's packed red cells and fresh frozen donor plasma. Encouraging results were obtained in these patients with cirrhosis and refractory coma.

Further methods of treatment are at present being examined but, as yet, it is too early to assess their effectiveness. Burnell et al. (1967) have performed cross circulation exchanges with some success, but with this method there are ethical difficulties in the choice of suitable partners and practical problems with donor reactions. Extra-corporeal circulation of patients' blood through an isolated perfused cadaveric liver (Sen et al., 1966) and heterologous perfusion using pig's liver (Eisman, Liem \& Raffucci, 1965) may produce some neurological improvement, but such measures require extensive facilities and have not been used in this country.

\section{The neurological syndromes in chronic liver disease}

During the last 15 years the spectrum of neurological disorders due to chronic liver disease has widened considerably (Williams \& Toghill, 1968). Attempts have been made to classify these syndromes into clinical sub-groups (Read et al., 1967) but such

TABLE 1

\begin{tabular}{|c|c|c|c|c|c|}
\hline & Patient & $\begin{array}{c}\text { Age } \\
\text { (years) }\end{array}$ & Diagnosis & Blood volume exchanged & Result \\
\hline 1. & F.A. & 37 & Viral hepatitis & $3600 \mathrm{ml}$ in $8 \mathrm{hr}$ & Died \\
\hline 2. & A.C. & 66 & Hepatitis,? halothane & $7200 \mathrm{ml}$ in 2 days & Survived \\
\hline 3. & W.B. & 68 & Hepatitis & $9600 \mathrm{ml}$ in 3 days & Died \\
\hline 4. & J.W. & 59 & $\begin{array}{l}\text { Portacaval shunt, } \\
\text { cirrhosis }\end{array}$ & $6600 \mathrm{ml}$ in 3 days & Initial improvement, \\
\hline 5. & A.H. & 60 & Cirrhosis & $3600 \mathrm{ml}$ in 2 days & Died, hepatoma \\
\hline
\end{tabular}


a classification is necessarily an artificial one and there is considerable overlap. Most patients show intellectual impairment which may progress to frank dementia whilst others have mood disturbances, hallucinations and paranoid delusions. The 'flappingtremor' is well recognized but some patients have Parkinsonian features and others bizarre choreaathetotic signs which may mimic Wilson's disease (Toghill, Johnstone \& Smith, 1967). Disturbances of the pyramidal system with spasticity and extensor plantar responses are common though unilateral signs have been observed (Pearce, 1963). Other syndromes include a demyelinating peripheral neuropathy (Dayan \& Williams, 1967), myelopathy (Liversedge \& Rawson, 1966) and optic atrophy (Ortiz-Vazquez, 1967).

Probably the most important recent advance in the understanding of chronic porto-systemic encephalopathy has stemmed from the work of Victor, Adams \& Cole (1965), who described a permanent neurological disorder which has been termed 'acquired hepato-cerebral degeneration'. This may occur with any type of cirrhosis with large natural or surgically induced portacaval shunts and may develop insidiously without preceding coma. These acquired hepato-cerebral degenerations differ from the types of porto-systemic encephalopathy described previously in that they do not fluctuate and are but poorly influenced by treatment. Furthermore, they are associated with structural neurological changes with an increase in number and size of the protoplasmic astrocytes and vacuolar degeneration of cells in the cortex, cerebellum and basal ganglia. Of course all types of porto-systemic encephalopathy may be precipitated or worsened by naturally occurring complications such as bleeding from varices or iatrogenic disorders. Diuretics, now often used vigorously for the treatment of ascites, may produce mental deterioration in as many as a third of patients although there may be no consistent pattern of electrolyte change (Sherlock et al., 1966). The routine administration of drugs and sedatives poses many difficulties and morphine in particular has an adverse effect both clinically and electroencephalographically (Laidlow, Read \& Sherlock, 1961).

Unfortunately most of the results of the newer lines of treatment in chronic porto-systemic encephalopathy have been disappointing. Most have been directed towards altering the bacterial flora in the large bowel to reduce the production of ammonia. Thus Lactobacillus acidophilus has been given in milk (Macbeth, Kass \& McDermott, 1965) or as the freeze-dried preparation Enpac (Read et al., 1966) and Fenton, Knight \& Humpherson (1966) administered a high-bacterial-content diet of milk and cheese and obtained some improvement in three patients. Changes in faecal $\mathrm{pH}$ produced by giving lactulose $(1,4 \beta$-galactosidofructose) have been reported as giving some benefit by Bircher et al. (1966). More recently Summerskill et al. (1968) have used acetohydroxamic acid, a urease inhibitor, in the treatment of chronic porto-systemic encephalopathy in man. Although significant reductions in the blood ammonia levels were obtained no consistent clinical effects were obtained. It seems likely that more permanent responses are likely to come from surgical exclusion of the colon by ileo-sigmoidostomy and whilst good neurological improvement has been obtained this is offset by the high mortality of this operation in the cirrhotic patient (Walker et al., 1965).

\section{References}

Bircher, J., Muller, J., Guggenheim, P. \& Haemmerli, U.P. (1966) Treatment of chronic portal-systemic encephalopathy with lactulose. Lancet, i, 890.

Burnell, J.M., Dawborn, J.K., Epstein, R.B., Gutman R.A., LeinbaCh, G.E., Thomas, E.D. \& VolWiler, W. (1967) Acute hepatic coma treated by cross-circulation or exchange transfusion. New Engl. J. Med. 276, 935.

Dayan, A.D. \& Williams, R. (1967) Demyelinating peripheral neuropathy and liver disease. Lancet, ii, 133.

EISEMAN, B., LIEM, D.S. \& RAFFUCCI, F. (1965) Heterologous liver perfusion in treatment of hepatic failure. Ann. Surg $162,329$.

Fenton, J.C.B., Knight, E.J. \& Humpherson, P.L. (1966) Milk and cheese diet in portal-systemic encephalopathy Lancet, i, 164.

Jones, E.A., Clain, D., Clink, H.M., MacGillivray, M: \& SHeRLock, S. (1967) Hepatic coma due to acute hepatic necrosis treated by exchange transfusion. Lancet, ii, 169.

Laidlow, J., Read, A.E. \& Sherlock, S. (1961) Morphine tolerance in hepatic cirrhosis. Gastroenterology, 40, 389.

LEE, C. \& TINK, A. (1958) Exchange transfusion in hepatic coma; report of case. Med. J. Aust. 1, 40.

LIVERSEDGE, L.A. \& RAwSON, M.D. (1966) Myelopathy in hepatic disease and porto-systemic venous anastomosis. Lancet, i, 277.

MAcbeth, W.A.A.C., Kass, E.H. \& McDermotT, W.V. (1965) Treatment of hepatic encephalopathy by alteration of intestinal flora with Lactobacillus acidophilus. Lancet, i, 399.

MORRIS, T.Q., Gocke, D.J. \& SARDI, G.F. (1967) Exchange transfusion treatment of fulminating viral hepatitis in the dog. J. clin. Invest. 46, 1098.

Ortiz-VAZQuez, J. (1967) Neuropathy and liver disease (Letter). Lancet, ii, 263.

PeARCE, J.M.S. (1963) Focal neurological syndromes in hepatic failure. Postgrad. med. J. 39, 653.

Read, A.E., McCarthy, C.F., Heaton, K.W. \& Laidlow, J. (1966) Lactobacillus acidophilus (Enpac) in treatment of hepatic encephalopathy. Brit. med. J. 1, 1267.

Read, A.E., Sherlock, S., Laidlow, J. \& Walker, J.G. (1967) The neuro-psychiatric syndromes associated with chronic liver disease and an extensive portal-systemic collateral circulation. Quart. J. Med. 36, 135.

SABIN, S. \& MERritT, J.A. (1968) Treatment of hepatic coma in cirrhosis by plasmapheresis and plasma infusion (plasma exchange). Ann. intern. Med. 68, 1.

SAmson, R.I., TReY, C., Timme, A.H. \& SAunders, S.J. (1967) Fulminating hepatitis with recurrent hypoglycaemia and haemorrhage. Gastroenterology, 53, 291. 
Sen, P.K., Bhalerao, R.A., Parulkar, G.P., Samsi, A.B., ShaN, B.K. \& KINARE, S.G. (1966) Use of isolated perfused cadaveric liver in the management of hepatic failure. Surgery, 59, 774.

Sherlock, S., Senewiratne, B., Scott, A. \& Walker, J.G. (1966) Complications of diuretic therapy in hepatic cirrhosis. Lancet, i, 1049.

Summerskill, W.H.J., Thorsell, F., Feinberg, J.H. \& ALDRETE, J.S. (1968) Effects of urease inhibition in hyperammonaemia. Gastroenterology, 54, 20.

Toghill, P.J., Johnston, A.W. \& SMITH, J.F. (1967) Choreoathetosis in porto-systemic encephalopathy. J. Neurol. Neurosurg. Psychiat. 30, 358.
Trey, C., Burns, D.G. \& Saunders, S.J. (1966) Treatment of hepatic coma by exchange blood transfusion. New Engl. J. Med. 274, 473.

Victor, M., Adams, R.D. \& Cole, M. (1965) The acquired (non-Wilsonian) type of chronic hepatocerebral degeneration. Medicine (Baltimore), 44, 345.

Walker, J.G., Emlyn-Williams, A., Graigie, A., RoseNOER, V.M., Agnew, J. \& SHerlock, S. (1965) Treatment of chronic portal-systemic encephalopathy by surgical exclusion of the colon. Lancet, ii, 861.

Williams, R. \& Toghill, P.J. (1968) The widening spectrum of neurological damage in liver disease. Postgrad. med. J. 44, 173 . 